\title{
Spondylitis in a humpback whale (Megaptera novaeangliae) from the southeast Pacific
}

\author{
Fernando Félix ${ }^{1,2, *}$, Ben Haase ${ }^{1}$, Windsor E. Aguirre ${ }^{1,3}$ \\ ${ }^{1}$ Fundación Ecuatoriana para el Estudio de Mamíferos Marinos (FEMM), PO Box 09-01-11905, Guayaquil, Ecuador \\ ${ }^{2}$ Pontificia Universidad Católica del Ecuador, Facultad de Ciencias Exactas y Naturales, Av. 12 de Octubre 1076 y Roca, \\ Quito, Ecuador \\ ${ }^{3}$ Department of Ecology and Evolution, State University of New York, Stony Brook, New York 11794, USA
}

\begin{abstract}
A $7.25 \mathrm{~m}$ long male humpback whale (Megaptera novaeangliae) with spondylitis was found beached on August 13, 1994 at Ancon, Ecuador $\left(2^{\circ} 23^{\prime} \mathrm{S}, 80^{\circ} 47^{\prime} \mathrm{W}\right)$. The condition involved at least 11 vertebrae, 7 lumbar (L4 to L11) and 4 caudal (Ca1 to Ca4). Partial fusion of vertebrae was observed as a result of intervertebral bony proliferation, likely impeding full motion. The relatively young age of this specimen and the severity of the deformities suggest an infectious, rather than degenerative, process. The gross findings are most consistent with some type of spondyloarthritis. Although this condition has previously been identified in a number of cetacean species, the pathogenesis, population impact and ecologic implications have not been fully assessed. This is the third case described for humpback whales and the first for a humpback whale from the SE Pacific.
\end{abstract}

KEY WORDS: Spondylitis $\cdot$ Humpback whale $\cdot$ Ecuador

Resale or republication not permitted without written consent of the publisher

\section{INTRODUCTION}

Vertebral anomalies have been widely documented both from captive (e.g. Morton 1978, Alexander et al. 1989) and wild cetaceans (e.g. Slijper 1936, Cowan 1966, Barcellos 1977, De Smet 1977, Paterson 1984, Kinze 1986, Gallo Reynoso \& Tovar Aguilar 1989, Kompanje 1995a, 1999, Sweeney et al. 2005), including a report from the fossil record of a primitive cetacean from the early Oligocene (Fordyce \& Watson 1998). Vertebral anomalies can result from a number of different pathogenic mechanisms, with different implications for the morbidity of the affected individuals. Some anomalies result from degenerative processes associated with aging (Kompanje 1995b), whereas others result from pathological entities and may affect young individuals, resulting in severe functional limitations and/or even death at pre-reproductive stages. Because there are gross similarities of vertebral changes, the terminology used to describe and provide morphologic diagnoses for the observed lesions varies considerably in the existing literature (Kompanje 1993, 1999).
Kompanje (1999) recognized 4 major classes of vertebral anomalies, including: (1) discarthrosis (or spondylosis deformans), a condition resulting in degeneration of the intervertebral disc often followed by bone changes such as the growth of marginal osteophytes that can be associated with normal aging processes; (2) infectious spondylitis (spondyloosteomyelitis), which results in irregular and sometimes massive bone growth around the vertebrae, destruction of 2 adjacent vertebral end-plates and vertebral fusion as a result of bacterial infection by a direct penetrating wound (e.g. Gallo Reynoso \& Tovar Aguilar 1989), bacteremia or bacterial infection spread from the urinary tract (Henson \& Coventry 1956); (3) diffuse idiopathic skeletal hyperostosis (DISH), which is a result of calcifications and ossifications of anterolateral ligaments of the vertebral column; and (4) spondyloarthritis, which includes several related conditions (ankylosing spondylitis, Reiter's syndrome, reactive arthritis, among others), the causes of which are unclear, although genetic components with a triggering infection have been implicated in some human conditions (e.g. Brewerton et al. 1973, Schlosstein et al. 
1973). Spondyloarthritis can also lead to irregular bone growth with severe pain and loss of mobility. With the exception of DISH, the other 3 conditions have been documented from cetaceans.

\section{MATERIALS AND METHODS}

In this report we describe a case of severe vertebral deformities in a $7.25 \mathrm{~m}$ beached, dead male humpback whale Megaptera novaeangliae. The animal was initially observed on August 13, 1994 near Ancon, Ecuador $\left(2^{\circ} 23^{\prime} \mathrm{S}, 80^{\circ} 47^{\prime} \mathrm{W}\right)$, and the partially decomposed carcass was examined the following day. The size of the Ecuadorian specimen indicates that this individual was probably an undersized yearling (see Stevick 1999) that had completed the first migrating roundtrip between the breeding area in tropical waters and the feeding area located in waters west of the Antarctic Peninsula (Stevick et al. 2004).

\section{RESULTS}

Externally, there was no evidence of trauma or attempted predation that would indicate a specific cause of death, but the carcass was covered by uncharacteristically large numbers of whale lice (Cyamus sp.), an ectoparasite specialized in feeding on whale skin (Slijper 1979). Lice were particularly abundant over the peduncular and genital remnants, giving the skin a pale brown coloration in these areas (Fig. 1).

The most significant gross finding involved the musculoskeletal system and was observed during the flensing process to obtain the skeleton ${ }^{1}$. A large portion of the lumbar and caudal vertebrae were fused and covered with a thick layer of irregular bone. The vertebral column was sectioned on the beach into several small blocks to facilitate transportation to a nearby area, where the blocks were buried for natural cleaning. Unfortunately, the block with most of the caudal vertebrae was lost during this period, and the condition of the final part of the spine could not be assessed. The remaining affected vertebral segments included 7 lumbar (L4 to L11) and 4 caudal (Ca1 to Ca4) vertebrae, approximately $1.5 \mathrm{~m}$ in total length (Fig. 2). There was a block of 4 fused lumbar vertebrae (L6 to L9), which likely formed an entire segment of 8 fused lumbar vertebrae (L4 to L11). The last 3 caudal vertebrae form another compact segment. The first caudal vertebra was less affected and did not form a

${ }^{1}$ The specimen is currently located at the FEMM Whale Museum in Salinas, Ecuador

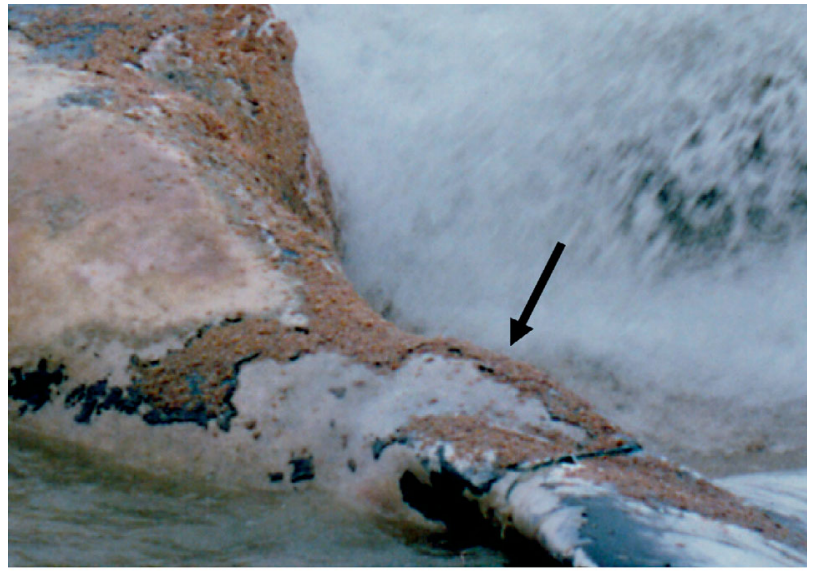

Fig. 1. Megaptera novaeangliae. Scattered brown patches formed by lice on the black epidermis of the whale, extending from the genital region to the central part of the tail. Note the irregularly enlarged and deviated peduncle (arrow)

contiguous segment with the proximally affected lumbar vertebrae. Ca1 was joined to Ca2 ventrally and through a small fractured syndesmophyte extending from the upper part of $\mathrm{Ca} 2$. It appears that the disease developed separately in the lumbar and caudal vertebrae and then extended towards the point at which the two converge. This supposition is also supported by the difference in appearance of the surrounding bone in the lumbar and caudal vertebrae. The bone growth around the lumbar vertebrae was more compact than around the caudal vertebrae, indicating that the lumbar area was in a more advanced stage of ossification (see Fig. 3). Because the entire last segment of caudal vertebrae was affected, it is likely that the condition extended to other caudal vertebrae beyond this point as well.

In most examined vertebrae, hyperostosis was circumferential, but asymmetrical around the external surface of the body and spinous processes (Fig. 3). In lumbar vertebra L5, the bone growth was thicker along the lateral and ventral sides and thinner around the neural arch. Based on this asymmetric bone proliferation, it is likely that the spondylitic change impinged upon both the neural cord and the hemal canal, resulting in pain, loss of mobility and reduced vascular perfusion. The epiphysis were completely fused to the vertebrae and deformed both dorso-ventrally (height) and laterally (width). The spinous process and the zygapophysis were not affected. Similar changes occurred in all remaining lumbar vertebrae, with the exception of L4. The pathology was also extensive in the caudal vertebrae. Hyperostotic bone was more prominent on both transverse processes of $\mathrm{Ca} 4$, with the right side more severely affected. The extra bone reached the 


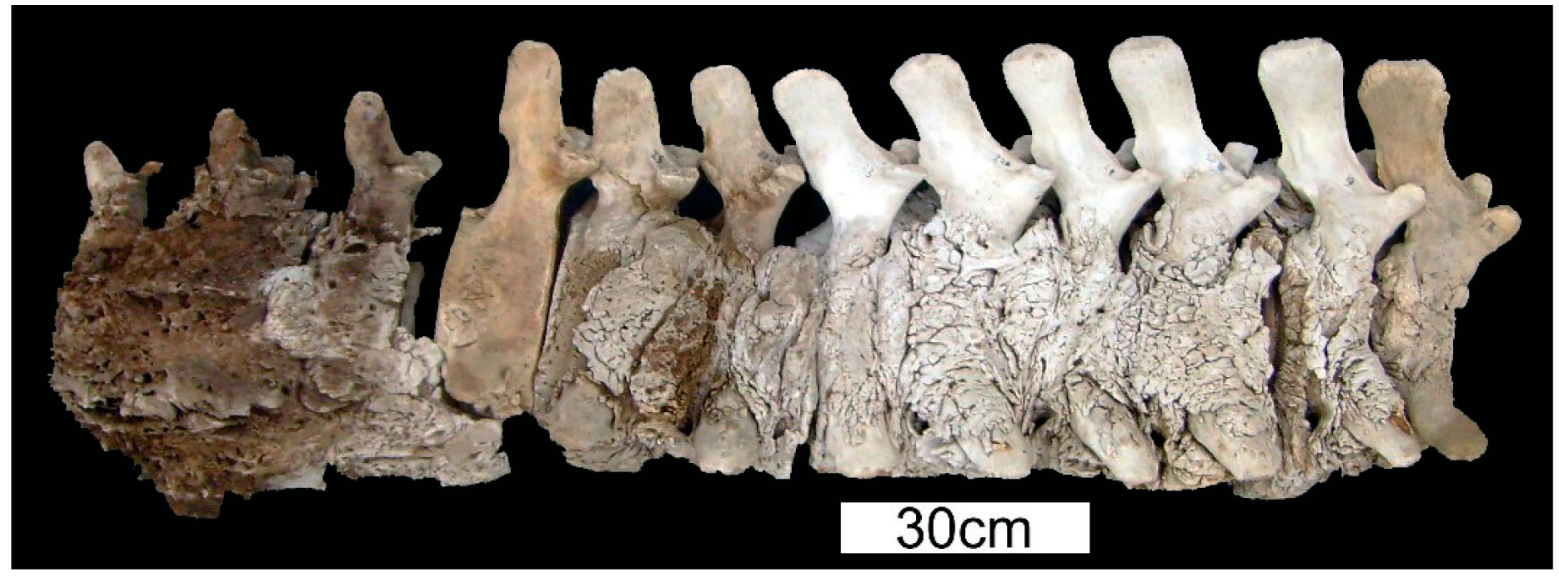

Fig. 2. Megaptera novaeangliae. Group of lumbar and caudal vertebra affected by spondylitis. The condition extended from L4 (right) to Ca4 (left)
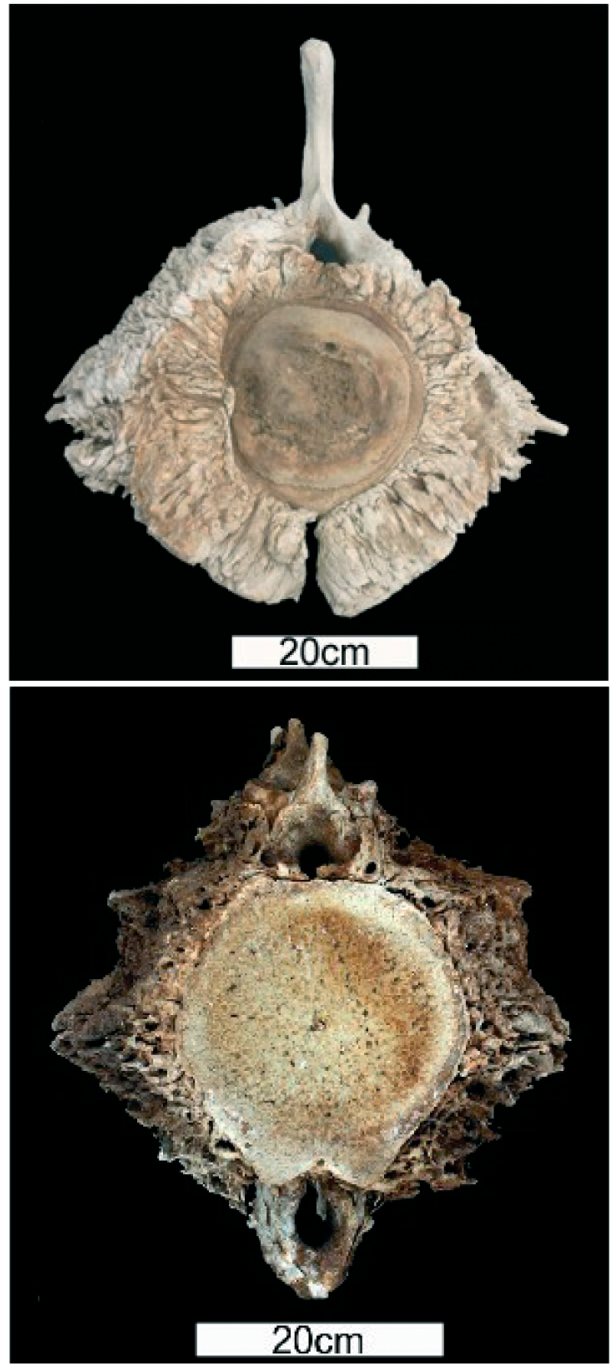

Fig. 3. Megaptera novaeangliae. Anterior view of lumbar vertebra L5 (top panel) and posterior view of caudal vertebra Ca4 (bottom panel), showing the extent of the hyperostotic condition spinous processes and covered the chevron bone, which was completely fused with the vertebra. Between $\mathrm{Ca} 2$ and $\mathrm{Ca} 4$, the neural canal was compromised, and, in $\mathrm{Ca} 3$, it was almost occluded. The chevron bone was fused in $\mathrm{Ca} 3$ and $\mathrm{Ca} 4$, but free in $\mathrm{Ca} 1$ and $\mathrm{Ca} 2$. The epiphysis was not fused on the posterior side of $\mathrm{Ca} 4$, but it was on the anterior side, as well as on both sides of Ca2 and Ca3.

Another part of the spine affected, although without vertebral fusion, was the cervical area. On the right side of the neural arch from Ca3 to T1, boney crestiform projections were present (Fig. 4). The skull and pectoral fin bones did not present signs of anomalous ossification.

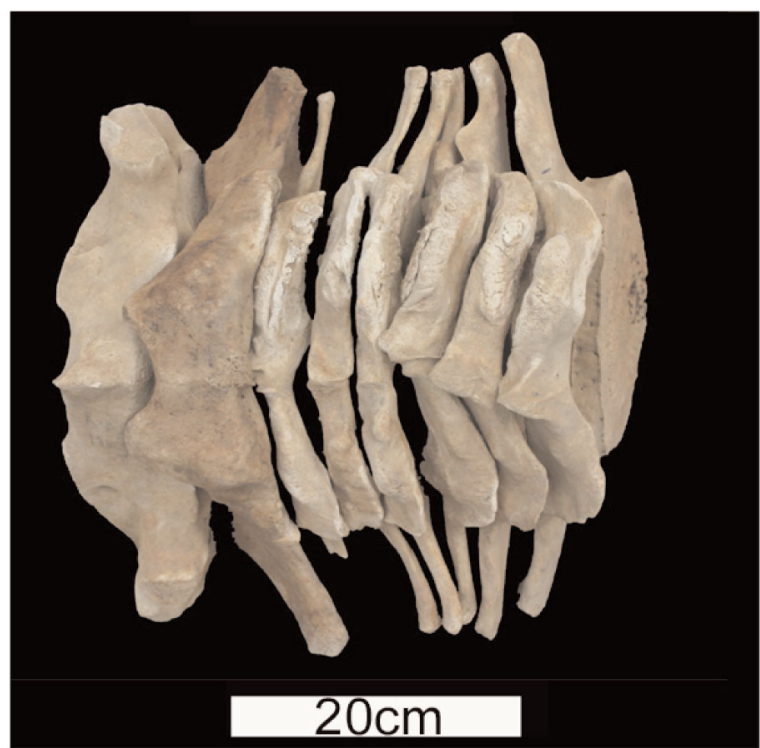

Fig. 4. Megaptera novaeangliae. Dorsal view of the cervical and first thoracic vertebrae showing the affected part in this area 


\section{DISCUSSION}

We believe that the pathology described in this specimen likely resulted from an infectious etiological agent because of the young age of the animal and the severity of the deformations. Spondyloarthritis is the pathology that best fits the described condition. Our findings are similar to recently described cases from other cetaceans with spondyloarthritis (Kompanje 1999, Sweeney et al. 2005). The presence of abnormal bone growth in the cervical area, although not involving fused vertebrae, also suggests an arthritic origin. Spondyloarthritis refers to a set of related conditions, the causes of which are unclear (e.g. Brewerton et al. 1973, Schlosstein et al. 1973). Because of the extent of involvement, Reiter's or ankylosing spondylitis are prime candidates. Both pathologies have similar origin in human beings and can appear during adolescence (Kompanje 1999, Resnick 2002). Reiter's syndrome, also called reactive arthritis, develops after an infection as a discontinuous spondylitic condition (Kompanje 1999); our specimen presented 2 series of fused vertebrae, one in the lumbar region and another in the caudal region. Ankylosing spondylitis is a form of chronic inflammation of the spine and sacroiliac joints (absent in cetaceans) that can lead to fusion of vertebrae (ankylosis) and may affect other organs such as eyes, heart, lungs, among others (Resnick 2002). Bacterial infections such as brucellosis and salmonellosis have been associated with spondylitis in human beings (Govender \& Schweitzler 2003, Pappas et al. 2005), dogs (Kornegay 1980) and snakes (Isaza et al. 2000). Brucella and Salmonella are common pathogens of marine mammals in both cetaceans and pinnipeds (Jahans et al. 1997, Higgins 2000); therefore, they are potential etiological agents in the Ecuadorian case. Other conditions considered were: discarthrosis (spondylosis), a degenerative disease occurring only in adult specimens (Kompanje 1995b), which can thus be ruled out; $\mathrm{DISH}$, excluded because the disease is located in the lower spine; and spondylo-osteomyelitis, which does not usually span $>2$ vertebrae (Sweeney et al. 2005) and is therefore also unlikely.

As mentioned above, the causes of spondyloarthritis are unclear, and we cannot rule out strictly environmental or congenital causes. Hypervitaminosis A, for example, has been associated with spondylosis and vertebral hyperostosis in captive/domestic mammals (Crawshaw \& Oyarzun 1996, Polizopoulou et al. 2005). Environmental pollution may also be a contributing factor in some cases (e.g. Beland et al. 1993). In our case, it was not possible to conduct histologic studies because of logistical limitations and lack of specialized veterinary facilities for such purposes. Without biochemical analysis, we could not screen for the hypothesized infectious etiological agent or determine if congenital malformations, nutritional deficiencies, or other natural processes predisposed to or were responsible for the vertebral anomalies described. Thus, our diagnosis remains tentative.

The prevalence of spondylitis in wild cetaceans has not been thoroughly analyzed and remains poorly understood, but it may have important ecological implications for some species. For example, Sweeney et al. (2005) found spondylitic lesions in pilot whales Globicephala melas stranded in Massachusetts, USA, and suggested that these lesions may be a contributing factor in the mass-stranding of highly sociable cetaceans. The bacterial origin of spondylitis in cetaceans may represent a risk for conspecifics as well as a zoonotic threat, especially if it is a consequence of an outbreak event. In the case of the humpback whale, which is not considered a social species, it is difficult to assess the implications of spondylitis, since no information exists on the level of incidence or typical origins of the disease. A severe spondylitic condition as reported here could be extremely detrimental to the fitness of affected individuals. This is not only true for humpback whales, but for cetaceans in general, since, unlike land mammals with rear legs, movement in cetaceans is generated by the up and down motion of the peduncle and the flukes (Slijper 1979); lumbar and caudal vertebral deformations could thus result in a severe loss of mobility in the spine, compromising the swimming ability of the animal.

The high level of infestation with lice (Cymus sp.) is also a sign that the whale moved slowly. Whales with reduced movement due to illness become infested with ectoparasites and epizoots (Fertl 2002). A heavily liceinfested and almost motionless humpback whale has been photographed in Hawaii, with an abnormality in the spine in the form of a protrusion with displacement to the right in the lumbar/caudal region (Osmond \& Kaufman 1998). The pathology of the Hawaiian and the Ecuadorian specimens was probably not caused by the same process, since in our specimen, although the peduncle appeared 'bulky', the individual did not show such marked displacement of the spine as in the Hawaiin case; nevertheless we suppose that both animals suffered from swimming problems. Whales with spine problems would also be more exposed to predation, because, besides being the main locomotion organ, the tail is also a major defense against their natural predator, the orca Orcinus orca (Chittleborough 1953).

For the above reasons, we consider that the stranding of the Ecuadorian whale is probably related to its advanced spondylitis, which likely compromised the ability of the animal to carry out vital activities such as swimming and feeding. During most of its short life it primarily fed on milk from its mother, which would not 
require much effort, but once weaned it may have run into problems foraging on live prey and become undernourished. Such conditions could favor the presence of the opportunistic infectious diseases that contributed to or caused its death.

To our knowledge, this is the third reported case of vertebral anomalies in a humpback whale and the first report from the southeastern Pacific. The other 2 cases include a specimen from Denmark, with a smooth calcification in 3 fused thoracic vertebrae (T5 to T7), originally described by Korschelt (1932) (Slijper 1936, Kompanje 1999), and the case of a $6.9 \mathrm{~m}$ female calf from Germany, with the last part of the spine affected by osteoperiostitis ossificans hypertrophicans (Stede 1994). The author describing this last case also suggested an infectious origin of the disease and that this condition was the primary cause of death. The Ecuadorian and German specimens demonstrate that spondylitis may affect young humpback whales, and, when it is not a direct result of an infection, it is even possible that it appears at an intra-uterine stage, as suggested by Slijper (1936). In the future, specific biochemical and bacteriological analyses of stranded whales may help to establish the level of incidence and pathogenesis of this type of lesions.

Acknowledgements. The authors thank FEMM volunteers who helped during the dissection work. We appreciate the collaboration of Professor Y. Shoenfeld, who encouraged us to write this article and who read the manuscript. Two anonymous reviewers made valuable comments to improve an earlier version of this article. The FEMM Whale Museum is partially financed by the Whale and Dolphin Conservation Society (WDCS).

\section{LITERATURE CITED}

Alexander JW, Solangi MA, Riegel LS (1989) Vertebral osteomyelitis and suspected diskospondylitis in an Atlantic bottlenose dolphin (Tursiops truncatus). J Wildl Dis 25(1):118-121

Barcellos LP (1977) Nota sobre osteopatologia em um exemplar de Hyperoodon planifrons (Ziphiidae-Cetacea), Rio Grande do Sul, Brasil. Atlantica 2(1):118-123

Beland P, Deguise S, Girard C, Lagace A and 7 others (1993) Toxic compounds and health and reproductive effects in St Lawrence beluga whales. J Gt Lakes Res 19:766-775

Brewerton DA, Oates JK, James DCO (1973) Reiter's disease and HL-A 27. Lancet 2:996-998

Chittleborough RG (1953) Aerial observations on the humpback whale Megaptera nodosa (Bonnaterre), with notes on other species. Aust J Mar Freshw Res 4:219-226

Cowan DF (1966) Pathology of the pilot whale Globicephala melaena. Arch Pathol 82:178-189

Crawshaw GJ, Oyarzun SE (1996) Vertebral hyperostosis in anteaters (Tamandua tetradactyla and Tamandua mexicana): probable Hypervitaminosis A and/or D. J Zoo Wildl Med 27:158-169

De Smet WMA (1977) The fate of old bottle-nosed dolphins, Tursiops truncatus, in nature as revealed by the condition of their skeletons. Aquat Mamm 5:78-88

Fertl D (2002) Barnacles. In: Perrin WF, Würsig B, Thewissen JGM (eds) Encyclopedia of marine mammals. Academic Press, San Diego, CA, p 75-78

Fordyce RE, Watson AG (1998) Vertebral pathology in an early Oligocene whale (Cetacea, ?Mysticeti) from Wharekuri, North Otago, New Zealand. Mainz Natwiss Arch Beih 21:161-176

Gallo Reynoso JP, Tovar Aguilar F (1989) Traumatismo vertebral en delfín común Delphinus delphis (Cetacean: Delphinidae) por inclusion de espina mantarraya Dasyatis sp. (Pisces: Dasyatidae). Vet Mex 20:277-279

Govender S, Schweitzler G (2003) Salmonella spondyitis in inflammatory disorders of the spine. In: Govender S (ed) Inflammatory diseases of the spine. TTG Asia Media Pty Ltd, Singapore, p 1-7

Henson SW Jr, Coventry MB (1956) Osteomyelitis of the vertebrae as the result of infection of the urinary tract. Surg Gynecol Obstet 1956:207-214

Higgins R (2000) Bacteria and fungi of marine mammals: a review. Can Vet J 41:105-116

Isaza R, Garner M, Jacobsen E (2000) Proliferative osteoarthritis and osteoarthrosis in 15 snakes. J Zoo Wildl Med 31:20-27

Jahans KL, Foster G, Broughton ES (1997) The characterisation of Brucella strains isolated from marine mammals. Vet Microbiol 16:373-382

Kinze CC (1986) Note on the occurrence of spondylitis deformans in a sample of harbour porpoises Phocoena phocoena (L.) taken in Danish waters. Aquat Mamm 12(1):25-27

Kompanje EJO (1993) Vertebral osteophytosis in Cetacea, spondylosis or spondylitis? Z Saeugetierkd 58:316-318

Kompanje EJO (1995a) On the occurrence of spondylosis deformans in white-beaked dolphins Lagenorhynchus albirostris (Gray, 1846) stranded on the Dutch coast. Zool Med Leiden 69:231-250

Kompanje EJO (1995b) Differences between spondylosteomyelitis and spondylosis deformans in small odontocetes based on museum material. Aquat Mamm 21:199-203

Kompanje EJO (1999) Considerations on the comparative pathology of the vertebrae in Mysticeti and Odontoceti; evidence for the occurrence of discarthrosis, zygarthrosis, infectious spondylitis and spondyloarthritis. Zool Med Leiden 73:99-130

Kornegay JN (1980) Diskospondylitis in dogs. J Am Vet Med Assoc 177(4):337-341

Korschelt E (1932) Über Frakturen und Skeletanomalien der Wirbeltiere. Beitr Pathol Anat Allg Pathol 89:419-483

Morton B (1978) Osteomyelitis (Pyogenic spondylitis) of the spine in a dolphin. J Am Vet Med Assoc 173:1119-1120

Osmond MG, Kaufman GD (1998) A heavily parasitized humpback whale (Megaptera novaeangliae). Mar Mamm Sci 14(1): 146-148

Pappas G, Akritidis N, Bosilkovski M, Tsianos E (2005) Brucellosis. N Engl J Med 352:2325-2336

Paterson RA (1984) Spondylitis deformans in a Bryde's whale (Balaenoptera edeni Anderson) stranded on the southern coast if Queensland. J Wildl Dis 20(3):250-252

Polizopoulou ZS, Kazakos G, Patsikas MN, Roubies N (2005) Hypervitaminosis A in the cat: a case report and review of the literature. J Feline Med Surg 7:363-368

Resnick D (2002) Ankylosing spondylitis. In: Resnick D (ed) Diagnosis of bone and joint disorders. Saunders, Philadelphia, PA, p 1023-1081

Schlosstein L, Terasaki PI, Bluestone R, Pearson CM (1973) High association of an HL-A antigen, W27, with ankylos- 
ing spondylitis. New Engl J Med 288:704

Slijper EJ (1936) Die Cetaceen vergleichend anatomisch und systematisch. Capita Zool VI, VII:1-590

Slijper EJ (1979) Whales. Cornell University Press, Ithaca

Stede M (1994) Zur Todesursache bei Walen der niedersächsischen Nordseeküste. Drosera 1/2:7-19

Stevick P (1999) Age-length relationship in humpback whales: a comparison of strandings in the western north Atlantic with commercial catches. Mar Mamm Sci 15(3):725-737

Editorial responsibility: Michael Moore,

Woods Hole, Massachusetts, USA
Stevick P, Aguayo A, Allen J, Avila IC and 15 others (2004) A note on the migrations of individually identified humpback whales between the Antarctic Peninsula and South America. J Cetacean Res Manag 6(2):109-113

Sweeney MM, Price JM, Jones GS, French TW, Early GA, Moore MJ (2005) Spondylitic changes in long-finned pilot whales (Globicephala melas) stranded on Cape Cod, Massachusetts, USA, between 1982 and 2000. J Wildl Dis 41(4):717-727

Submitted: October 17, 2006; Accepted: February 12, 2007 Proofs received from author(s): March 29, 2007 